\title{
Editorial Comment: Study of kidney morphologic and structural changes related to different ischemia times and types of clamping of the renal vascular pedicle
}

\author{
Luciano A. Favorito 1, 2, 3 \\ ${ }^{1}$ Professor Titular, Unidade Urogenital da Univ. Est. do Rio de Janeiro - UERJ, RJ, Brasil; ${ }^{2}$ Urologista \\ do Hospital da Lagoa Federal, Rio de Janeiro , RJ, Brasil; ${ }^{3}$ Editor Associado do International Braz J Urol
}

Mazzeo and collegues from Sao Paulo - Brazil shows in a very interesting paper the morphologic and structural changes of renal parenchyma during the clamping of the renal pedicle. Partial nephrectomy (open, laparoscopic or robotic) is considered the gold standard for treating localized renal tumors (1-6). Warm renal ischemia is commonly performed during partial nephrectomy to achieve a bloodless surgical field, however renal ischemia has been associated with renal function impairment (7).

Previous studies shows that the swine is the most adequate model for comparison to human kidney anatomy and physiology $(8,9)$. Traditionally, 30 minutes is considered the maximum safe time for renal warm ischemia. In a recent study with swine model (10), the renal warm ischemia of 30 minutes by arterial clamping did not caused significant glomerular damage or nephron loss, but if an artery and vein (en bloc) clamping was used, the 30 minutes of warm ischemia caused a decrease in the number of glomeruli.

In the present paper the authors shows that the number of renal parenchymal lesions derived from ischemia is associated with the duration of the insult, but a interesting result was the significant difference between the types of clamping, and the group with clamping of artery and vein presented a lower frequency of injuries than the group with only the renal artery clamping.

According the results of this experimental study during a partial nephrectomy, the en bloc clamping for warm ischemia should be favored over only the renal artery clamping to minimize renal injury after partial nephrectomies, but more studies will be necessary in the future to confirm these results.

\section{REFERENCES}

1. Mazzeo A, Sincos APWB, Leite KRM, Góes MA Jr, Dos Pavão OFS, Kaufmann OG. Study of kidney morphologic and structural changes related to different ischemia times and types of clamping of the renal vascular pedicle. Int Braz $\mathrm{J}$ Urol. 2019;45:754-62.

2. Volpe A, Cadeddu JA, Cestari A, Gill IS, Jewett MA, Joniau S, et al. Contemporary management of small renal masses. Eur Urol. 2011;60:501-15.

3. Porreca A, D’Agostino D, Dente D, Dandrea M, Salvaggio A, Cappa E, et al. Retroperitoneal approach for robot-assisted partial nephrectomy: technique and early outcomes. Int Braz J Urol. 2018;44:63-8.
4. Lanchon C, Arnoux V, Fiard G, Descotes JL, Rambeaud JJ, Lefrancq JB, et al. Super-selective robot-assisted partial nephrectomy using near-infrared flurorescence versus early-unclamping of the renal artery: results of a prospective matched-pair analysis. Int Braz J Urol. 2018;44:53-62.

5. Tachibana H, Takagi $T$, Kondo $T$, Ishida $H$, Tanabe $K$. Comparison of perioperative outcomes with or without renorrhaphy during open partial nephrectomy: A propensity score-matched analysis. Int Braz J Urol. 2018;44:467-74.

6. Bertolo R, Fiori C, Piramide F, Amparore D, Porpiglia F. The preoperative stratification of patients based on renal scan data is unable to predict the functional outcome after partial nephrectomy. Int Braz J Urol. 2018;44:740-9. 
7. Mir MC, Ercole C, Takagi T, Zhang Z, Velet L, Remer EM, et al. Decline in renal function after partial nephrectomy: etiology and prevention. J Urol. 2015;193:1889-98.

8. de Souza DB, de Oliveira LL, da Cruz MC, Abílio EJ, Costa WS, Pereira-Sampaio MA, et al. Laparoscopic partial nephrectomy under warm ischemia reduces the glomerular density in a pig model. J Endourol. 2012;26:706-10.

9. Damasceno-Ferreira JA, Bechara GR, Costa WS, PereiraSampaio MA, Sampaio FJB, Souza DB. The relationship between renal warm ischemia time and glomerular loss. An experimental study in a pig model. Acta Cir Bras. 2017;32:334-41.
10. Bechara GR, Damasceno-Ferreira JA, Abreu LAS, Costa WS, Sampaio FJB, Pereira-Sampaio MA, et al. Glomerular Morphology and Renal Function after Warm Ischemia by Main Artery or Selective Clamping in a Porcine Model. Urol Int. 2017;99:262-6.

Correspondence address: Luciano Alves Favorito, MD, PhD Rua Professor Gabizo, 104 / 201 Tijuca, Rio de Janeiro, 20271-320, Brasil Fax: +55 21 3872-8802 E-mail: lufavorito@yahoo.com.br

ARTICLE INFO

Luciano A. Favorito http://orcid.org/0000-0003-1562-6068

Int Braz J Urol. 2019; 45: 763-4

Submitted for publication: May 25, 2019

Accepted after revision:

May 30, 2019

Published as Ahead of Print: June 20, 2019 